\title{
The context of clinical teaching and learning in Australia
}

\begin{abstract}
Julie K Ash BSc(Hons), BM BS, PhD, Lecture

Lucie K Walters MB BS, PhD, FACRRM Associate Professor Flinders University Rural Clinical School

David J Prideaux BA(Hons), MEd, PhD Emeritus Professor

Ian G Wilson MB BS, PhD, FRACGP Professor

1 Health Professiona Education, School of Medicine, Flinders University, Adelaide, SA.

2 Medical Education Unit, University of Western Sydney, Sydney, NSW.

david.prideaux@ flinders.edu.au
\end{abstract}

doi: 10.5694/mjal0.11488

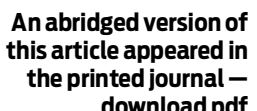
download pdf

Series Guest Editor

Jennifer J Conn FRACP, MClinEd, BSc(Hons)

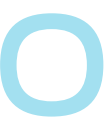

ne of the enduring strengths of medical education is that a considerable proportion of the training of future doctors is devoted to teaching, learning and experience in real clinical environments. Traditionally, this has taken place in teaching hospitals in the context of strong reciprocal relationships with medical schools. Recently, the teaching hospital model in Australia has been subject to some strain; the increasing specialisation of medical practice and workload pressures have reduced the time available for education. At the same time, Australian medical students have had increased opportunities to undertake clinical learning in general practice, and in rural and community settings.

We present a framework for symbiotic clinical education, arising in part from research evidence from a year-long, rural, longitudinal, clinical education program. We believe that this framework provides a useful basis for reconstructing clinical learning in teaching hospitals.

\section{Teaching hospitals and traditional clinical learning}

In the 100 years since Abraham Flexner's seminal report, ${ }^{1}$ the academic medical centre or teaching hospital has been the main context for learning, teaching and practising medicine. Medical schools have developed close and interlocked relationships with teaching hospitals. A sense of place or context is important in pedagogy ${ }^{2}$ and, in Australia, establishing that sense of place helps to bring medical education and the health system closer together.

One of the fundamental premises of teaching hospitals in Australia is that students are taught by, and learn from, all clinical staff, and not just from those on the medicalschool payroll. Thus, the system has been predicated on much in-kind teaching by health service staff. Teaching hospitals are specialist centres and attract high-quality staff as teachers, mentors and role models. In the past, they have provided the context for clinical care sufficiently comprehensive for students to receive a thorough preparation for future medical practice.

Clinical learning in teaching hospitals is based on the apprenticeship model — learning from patient contact with the clinician-patient-student triad being the essential unit of this model, and providing the context for "the teaching moment". Teaching and patient care are inextricably intertwined.

Teaching hospitals in Australia and elsewhere, however, are facing significant challenges. ${ }^{3-5}$ There is an increasing focus on tertiary- and quaternary-care services, with most patients admitted to hospital having more severe illness, often requiring acute or emergency care. Moreover, many

\begin{abstract}
Summary
- Gaining clinical experience for an extended period of time in teaching hospitals is one of the enduring strengths of medical education.

- Teaching hospitals have recently faced significant challenges, with increasing specialisation of services and workload pressures reducing clinical learning opportunities.

- New clinical teaching environments have been established in Australia, particularly in rural and regional areas; these are proving to be ideal contexts for student learning.

- The new clinical teaching environments have shown the importance of developing symbiotic relationships between universities and health services. Symbiotic clinical learning is built around longitudinal, patientbased learning emphasising priority health concerns.

- The symbiotic framework provides a basis for reconstructing clinical teaching in teaching hospitals so that they continue to play a vital role in Australian medical education, with additional clinical experience provided by primary care and community, rural and regional hospitals.
\end{abstract}

undergo complex technological investigations or treatments. As governments seek to reduce public hospital costs, patients often do not stay long in hospital. All these factors reduce the opportunities for in-kind teaching.

In a recent study of a major teaching hospital, ${ }^{6}$ clinicians reported concerns that clinical teaching was no longer valued within hospitals. Service demands were high, and services had become increasingly specialised and fragmented. Maintaining an apprenticeship focus in clinical teaching had become more difficult, as students were required to rotate through multiple subspecialty units to cover the curriculum. Compounding this were changes in medical school curricula and greater demands on student time. The study identified the importance of the tight nexus between the structure of the clinical service and the structure of clinical teaching. The relationship between the medical school and the health service was put under increasing pressure as the governance structures of the two bodies diverged, and the critical element of the apprenticeship system - continuity - was lost in the tertiary teaching hospital context: continuity of student-teacher contact; of student-patient contact; and of student-health service contact. Students no longer experienced the full apprenticeship and no longer became part of the clinical community.

There have been moves to restore the pre-eminence of clinical teaching in teaching hospitals. The much respected "Teaching on the run" program 7 emphasises an approach to clinical teaching across the medical student-junior doctor 
continuum within busy and complex work environments. More work needs to be done, however, to maximise teaching and learning opportunities in these clinical environments that have changed considerably since Flexner's direction-setting report.

\section{Clinical learning in rural and community health} services

Over the past few decades, the need for comprehensive, people-orientated, coordinated health services with a focus on multisystem care and long-term care has been increasing. ${ }^{8}$ Much of this care occurs not in teaching hospitals, but in community, primary care and ambulatory settings. Not surprisingly, medical schools have turned their attention to the opportunities for clinical placements in these settings.

In Australia, the most important recent change to clinical teaching and learning has come from establishing rural clinical schools and placing significant numbers of students for extended periods in regional and rural hospitals and in community general practices. ${ }^{9}$ While the establishment of rural clinical schools was initially motivated by the need to attract students to rural practice, these schools have provided a context for clinical teaching in smaller and less specialised environments than those in urban teaching hospitals. Smaller district general hospitals have been reported to have more friendly and supportive environments and more opportunities for hands-on learning. ${ }^{10}$ In addition, the comprehensive general practices in rural areas provide clinical educational experiences of longer duration, with a focus on generalism and continuity (longitudinal, integrated programs). During extended placements, students can learn in a continuous and integrated manner by following patients from primary care to inpatient settings, while at the same time building close relationships with their supervisors, other health professionals, patients and community members.

There is emerging evidence from these programs (such as the Parallel Rural Community Curriculum, the year-long rural general practice-based program of the School of Medicine at Flinders University) that students become more immersed in their clinical environments, experience greater patient contact and receive more supervision than their city-based teaching-hospital peers. Importantly, their performance is superior in end-of-year written and clinical assessments. These assessments are taken by all students irrespective of their paths of clinical learning - urban teaching hospitals, regional hospitals or longitudinal general practices. ${ }^{11-14}$

Rural and regional hospitals do not have the same degree of specialisation as urban teaching hospitals, making them ideal for medical student learning. They have clinical service pressures, however, and their clinicians also must deal with the competing demands of service and teaching. Thus, the same questions arise about the long-term sustainability of teaching and learning that relies on significant input from clinicians. In addition, the increasing numbers of students allocated to rural and regional hospitals may threaten the close relationships between students and their supervisors that have been a hallmark of such programs.
Rural general practices also offer a comprehensive scope of practice for student learning. As in urban general practices, the presence of students has the potential to result in general practitioners seeing fewer patients, resulting in a loss of income greater than the compensation provided through Practice Incentive Payments. Recent research shows, however, that by adopting a model of parallel consulting, rural GPs are in fact able to see the same number of patients while precepting students as they would in the absence of students. ${ }^{15}$ In the parallel consulting model, the GP and student initially see a patient separately, and then come together for a joint consultation with the patient before working separately again. Consultation time-management analysis indicates that the nature of the consultation changes, with a greater emphasis on history-taking in shared consultations, compared with the GP's usual management of patient consultations. ${ }^{16}$

Continuity of care enhances opportunities for patients to gain confidence in students, for students to respond to the relationships they develop with patients, and for students to feel responsible for patient outcomes and to advocate for patients. Moreover, clinicians can move beyond teaching-on-the-run skills to efficiently and effectively teach students while treating patients. In this setting, students have a legitimate role in the work of their clinical supervisors, and GPs can step back and take primary responsibility for orchestrating the quality and safety of the consultation. Students can then provide the major part of the patients' management, with most of their learning coming from taking an active role in patient care. ${ }^{17}$

Longitudinal, community-based programs generate additional costs for student support and supervision, as well as for information technology and infrastructure (including constructing additional rooms for parallel consulting). The additional funds provided through rural clinical schools have been important in meeting these needs. Furthermore, the funds are transparent, which is not always the case with funding provided to urban teaching hospitals.

\section{Symbiosis in clinical teaching}

Symbiosis is one of the elements in the acronym PRISMS, representing the key directions for medical education in the 21st century: product-focused, relevant, interprofessional, shorter courses/smaller numbers of students, multisite and symbiotic. ${ }^{18}$

We support the notion that contemporary medical education should be underpinned by symbiotic or mutually reinforcing relationships between medical schools and their associated health services. Students gain good learning opportunities, while the health services benefit from the contributions of students and the medical school. In many respects, it is this type of relationship that defined the formation of Flexner's academic medical centres, but this relationship has been weakened by the changed circumstances of medical schools and health services.

A framework for symbiotic medical education has been developed, grounded in study of the Parallel Rural Community Curriculum at Flinders University. ${ }^{19}$ The model includes four fundamental relationships (Box): 
- Between personal principles and professional expectations of clinical learners and their supervisors. Compared with short rotations, longitudinal placements provide more opportunities for students to build the personal and professional relationships with clinicians, patients and others that will strengthen their learning experience.

- Between clinicians and patients. Patient-based learning is predicated on the strength of the clinician-patient relationship and the relationships students build when learning from clinicians and patients.

- Between universities and health services. The health service provides the context for authentic student learning and an opportunity to contribute to patient care, while the university provides the essential support for learners and teachers.

- Between governments and communities. Governments and communities have expectations of health services. Clinical education, emphasising priority health concerns, assists in meeting these expectations.

Thus, the key concepts in a renewed approach to clinical teaching and learning become longitudinal placements; patient-based learning; authentic supported learning; and priority health concerns. ${ }^{20}$

Research has shown that some of these principles can be successfully applied during a 6-week orthopaedic rotation in an acute hospital. In particular, increased continuity was achieved by making patients the focus of students' learning rather than having them follow individual consultants. Students were involved in all aspects of preoperative, operative and postoperative care, including presentation of case reports at the regular multiprofessional team meetings. These activities provided students with useful roles supporting patient care within the clinical service.

\section{Reconstructing clinical learning in teaching hospitals}

Key concepts from the symbiotic framework could provide a basis for reconstructing clinical teaching and learning in larger teaching hospitals. This could help ensure that these hospitals continue to provide meaningful and comprehensive clinical education - the important part of their central purpose that has become increasingly difficult to maintain.

Longitudinal integrated experiences are difficult to provide when most patients have short hospital stays. A similar experience, however, could be achieved by allocating each student to a panel of patients from across the medical specialties. Students could follow their patients through the acute illness episode to discharge and beyond, as their further care is undertaken in community settings.

Providing a focus on learning from patients may assist in overcoming some of the fragmentation of student learning. Patients become the constant element. Students would be able to learn from patients, and from all the clinical staff involved in patient care as care is being delivered. The student would be in the centre of a circle of learning opportunities for all clinical team members. ${ }^{22}$ Parallel consulting in outpatient clinics provides opportunities for students to interact with patients on their own, then jointly with consultants and registrars.

Teaching hospitals can provide abundant opportunities for authentic student learning. The key is to ensure that the



Adapted, with permission, from: Worley P. Integrity: the key to quality in community-based medical education? Educ Health 2002; 15: 129-138.

learning is embedded in the real work of the hospital's clinicians and provides useful roles for students in the patient care team. Concepts of "hot" action, or action central to patient care, and "cold" action, involving feedback, discussion and reflection, are both important. ${ }^{22}$ In a symbiotic relationship, it is the responsibility of the medical school to support the organisational and affective dimensions of this learning, ranging from the routine tasks of scheduling placements to managing the profound responses that challenges to personal values and ethical dilemmas can elicit in students. Teaching hospitals, as part of health services, must meet the health needs of their communities and the health priorities of the funding governments. Clinical teaching and learning should be firmly embedded in those needs and priorities. The relationship between medical schools and teaching hospitals could be strengthened if medical schools were able to assist teaching hospitals in meeting their governmental and community expectations. While firmly located in the clinicianstudent-patient triad, clinical learning should relate to a framework of the common presentations and health priorities of the hospital and health services.

\section{Future contexts for clinical teaching}

There is no doubt that sustained clinical teaching and learning remains fundamental to Australian medical education. Situated learning is powerful, ${ }^{23}$ and clinical education should be embedded in the everyday activities of patient care. However, clinical teaching and learning is changing, and recent studies in rural and community settings have indicated directions for change. At the same time, the apprenticeship mode of teaching and learning, the traditional strength of the teaching hospital, needs to be reconstructed so that it remains pivotal in the changed service conditions of large urban hospitals. 
Clinical teaching has expanded beyond the teaching hospital environment, with recognition of the importance of general practice in medical education and the opportunities for students in rural clinical schools. There are two compelling reasons for this trend to continue:

- More places are needed to accommodate the increased number of students from the recent expansion of medical schools and medical student places; and

- As large hospitals become more specialised, and as the prevalence of chronic illness increases, more patients will receive most of their care outside teaching hospitals.

Teaching hospitals with reconstructed apprenticeship learning will continue to be important for clinical learning. But students are also likely to receive their clinical education in smaller, rural and community hospitals; private hospitals; public and private ambulatory clinics; urban, outer-urban and rural general practices; and community health centres. There are already plans and facilities for substantial clinical learning within the GP Plus Super Clinics and GP Super Clinics. One of the functions of Health Workforce Australia is to identify new clinical teaching environments. ${ }^{24}$

Flexner's legacy was strong academic medical centres. Clinical education of the future, however, will take place in a greater variety of health care contexts, underpinned by concepts of continuity, patient-based learning and engagement in health care as a basis for learning, and with a focus on priority health needs.

Competing interests: No relevant disclosures.

Provenance: Commissioned; externally peer reviewed.

1 Flexner A. Medical education in the United States and Canada: a report to the Carnegie Foundation for the Advancement of Teaching. Boston: Updyke, 1910. (Carnegie Foundation Bulletin No. 4.) http://www.carnegiefoundation.org/ sites/default/files/elibrary/Carnegie_Flexner_Report.pdf (accessed Jan 2012).

2 Gruenewald DA. Foundations of place: a multi-disciplinary framework for place-conscious education. Am Educ Res J 2003; 40: 619-654.

3 Prideaux DJ, Marshall VR. A "common" surgery curriculum: health care delivery and undergraduate surgical education in Australian teaching hospitals. World J Surg 1994; 18: 657-661.

4 Crotty BJ. More students and less patients: the squeeze on medical teaching resources [editorial]. Med J Aust 2005; 183: 444-445.

5 Cooke M, Irby DM, Sullivan W, Ludmerer KM. American medical education 100 years after the Flexner report. N Engl J Med 2006; 355: 1339-1344.
6 Ash J. A case of meaning: change in clinical education [PhD thesis]. Adelaide: Flinders University, 2010.

7 Lake FR. Teaching on the run tips: doctors as teachers. Med J Aust 2004; 180 : 415-416.

8 Starfield B. Global health, equity and primary care [commentary]. J Am Board Fam Med 2007; 20: 511-513.

9 Lennon B. Medical workforce expansion in Australia: commitment and capacity. 9th International Medical Workforce Collaborative Conference; 2005 Nov 15-19; Melbourne, Australia. http://www.rcpsc.edu/publicpolicy/imwc/9 expansion_oz.pdf (accessed Jan 2012).

10 Parry J, Mathers J, Al-Fares A, et al. Hostile teaching hospitals and friendly district hospitals; final year students' views on clinical attachment locations. Med Educ 2002; 36: 1131-1141.

11 Worley P, Esterman A, Prideaux DJ. Cohort study of examination performance of undergraduate students learning in community settings. BMJ 2004; 328: 207-209.

12 Worley P, Prideaux DJ, Strasser R, et al. Empirical evidence for symbiotic medical education: a comparative analysis of community and tertiary-based programmes. Med Educ 2006; 40: 109-116.

13 Worley P, Strasser R, Prideaux DJ. Can medical students learn specialist disciplines based in rural practice? Lessons from students' self reported experience and competence. Rural Remote Health [internet] 2004; 4: 338. Epub 2004 Nov 23.

14 Worley P, Prideaux DJ, Strasser R, et al. What do students actually do on clinical rotation? Med Teach 2004; 26: 594-598.

15 Walters L, Worley P, Prideaux DJ, Lange K. Do consultations in rural general practice take more time when practitioners are precepting medical students? Med Educ 2008; 42: 69-73.

16 Walters L, Prideaux D, Worley P, et al. What do general practitioners do differently when consulting with a medical student? Med Educ 2009; 43: 268273.

17 Walters L, Prideaux D, Worley P, Greenhill J. Demonstrating the value of longitudinal integrated placements for general practice preceptors. Med Educ 2011; 45: 455-463.

18 Bligh J, Prideaux D, Parsell G. PRISMS: new educational strategies for medical education [editorial]. Med Educ 2001; 35: 520-521.

19 Worley P. Relationships: a new way to analyse community-based medical education? (Part one). Educ Health 2002; 15: 117-128. http:// www.educationforhealth.net/EfHArticleArchive/1357-6283_v15n2s4 713665108.pdf (accessed Jan 2012)

20 Prideaux D, Worley P, Bligh J. Symbiosis: a new model for medical education. Clin Teach 2007; 4: 209-212.

21 Bramwell D. Longitudinal patient contact for students on surgical rotation. Annual Conference of the Association for Medical Education in Europe (AMEE); 2009 Aug 29-Sep 2; Málaga, Spain.

22 Hoffman KG, Donaldson JF. Contextual tensions of the clinical environment and their influence in teaching and learning. Med Educ 2004; 38: 448-454.

23 Lave J, Wenger E. Situated learning: legitimate peripheral participation. New York: Cambridge University Press, 2007: 91-97.

24 Health Workforce Australia. National health workforce innovation and reform strategic framework for action 2011-2015. Adelaide: HWA, 2011. https:// www.hwa.gov.au/sites/uploads/hwa-wir-strategic-framework-for-action201110.pdf (accessed Mar 2012). 